\title{
MACRO DETERMINANTS OF THE REAL EXCHANGE RATE IN A SMALL OPEN SMALL ISLAND ECONOMY: EVIDENCE FROM MAURITIUS VIA BMA
}

\author{
Bernard Njindan Iyke ${ }^{1}$ \\ ${ }^{1}$ Centre for Financial Econometrics, Deakin Business School, Victoria, Australia. \\ E-mail: bnjindan@deakin.edu.au
}

\begin{abstract}
We assess the robust macro determinants of the real exchange rate in Mauritius under model uncertainty by utilizing Bayesian Model Averaging (BMA). We introduce a broader range of potential macro determinants of the real exchange rate in Mauritius. Then we tackle the issue of model uncertainty when identifying these macro determinants of the real exchange rate by exploring the impact of different priors on the model size, and different priors on model coefficients on the posterior estimates. We identify the real money supply, and the real productivity to be the robust macro determinants of the real exchange rate in Mauritius. Their coefficient signs are also theoretically consistent. The real money supply impact on the real exchange rate negatively, whereas the real productivity impact on it positively. Our results remain robust to different priors on the model size, and to different priors on model coefficients.
\end{abstract}

Keywords: Model uncertainty; Bayesian Model Averaging (BMA); Macro determinants, Real exchange rate; Mauritius.

JEL Classification: C11; C15; F31.

Article history:

Received : March 2, 2018

Revised : April 30, 2018

Accepted : July 29, 2018

Available online : July 31, 2018

https://doi.org/10.21098/bemp.v21i1.922 


\section{INTRODUCTION}

This paper explores the macro determinants of the real exchange rate in Mauritius for the period 1976-2012. Various studies, today, have focused on identifying the fundamental drivers of the real exchange rate. ${ }^{2}$ This is understandable because the real exchange rate, which, to a very large extent, dictates trade flows and international competitiveness, may lose its value if it determinants are not known (see Kia, 2013). On this premise, understanding the macroeconomic determinants of the real exchange rate is, therefore, very important for monetary policymakers, since the influence of the real exchange rate on the real economy can only be sufficiently assessed if the sources of shocks that drive it are known (see Detken et al., 2002).

In the literature, the issue that resurfaces frequently is the approach used to estimate the links between the real exchange rate and its macro determinants. For example, under the Purchasing Power Parity (PPP) approach, the long-run real exchange rate is assumed to be stationary so that any deviation from this rate reflects misalignment. Thus, the determinants of the real exchange rate are the shocks that drive it from the equilibrium rate. This notion has, however, been heavily criticized due to the slow mean-reverting property of the real exchange rate (see MacDonald and Ricci, 2003). The Behavioural Equilibrium Exchange Rate (BEER) approach as introduced by Clark and MacDonald (1999) contends, instead, that the real exchange rate and its determinants should be viewed as I(1) processes. This means that cointegration analysis can be utilized to assess the influence of the determinants on the real exchange rate (see Elbadawi and Soto, 1994; Edwards, 1994; Cardenas, 1997; Montiel, 1997; Loayza and Lopez, 1997; Aron et al., 2000; MacDonald and Ricci, 2003; Iman and Minoiu, 2011). Some researchers prefer to setup and simulate a dynamic general equilibrium macroeconomic model using parametric calibration and data suitable for a given country (see Clark et al., 1994; Williamson, 1994; Stein et al., 1995). Other researchers utilize single equation models and partial equilibrium models to examine the movement of the real exchange rate in the long-run (see Driver and Wren-Lewis, 1997; Ghei and Pritchett, 1999).

The current paper brings some new contributions into the literature. First, when compared to the existing studies, the paper utilizes a much broader range of potential macro determinants (i.e. 21 potential macro determinants) of the real exchange rate for a small open economy, Mauritius. To the best of our knowledge, this is the first paper to do so. Second, the paper tackles the issue of model uncertainty when identifying these macro determinants of the real exchange rate. The paper does this by exploring the impact of different priors on the model size, and different priors on model coefficients on the posterior estimates. When the BMA approach is utilized this way, the paper avoids unintended consequences of eliciting inappropriate priors, and dealing sufficiently with multicollinearity issues.

2 A survey of earlier papers can be found in MacDonald (1995), Rogoff (1996), and Hinkle and Montiel (1999). For a very recent survey, see Lee et al. (2008). 
The remaining sections of this paper are structured as follows. Section II briefly explores the exchange rate history of Mauritius. Section III presents a simple model of the real exchange rate. Section IV presents the model specification and the prior structures of the BMA approach. Section V presents the empirical results. Section VI concludes the paper.

\section{A BRIEF HISTORY OF THE EXCHANGE RATE POLICY OF MAURITIUS}

Mauritius has practiced fairly mixed exchange rate regimes from independence to date. Prior to independence in 1968, the country shifted from a currency board system to a pegged system in November 1967. The Mauritian currency, the rupee, was pegged to the British pound (see IMF, 2008; Imam and Minoiu, 2011). Under this pegged system, the country employed a dual exchange market. All capital account transactions were separated from current account transactions. To this end, all capital transfers attracted a stamp duty of $15 \%$ under the pegged system (see Imam and Minoiu, 2011).

In June 1972, Mauritius created a central exchange rate with Special Drawing Rights (SDRs), following the weakening of the British pound in 1971. However, the second exchange rate for capital transfers remained in place. The rupee was officially pegged to the SDR in January 1976 around a bandwidth of $2 \%$. This was the case in theory but the rate was actually a crawling band around the US dollar (see Imam and Minoiu, 2011). Between 1976 and 1978, the rupee was considered overvalued. Thus, the Bank of Mauritius undertook devaluation exercises in 1979 and 1981. That apart, the stamp duty was increased from $36 \%$ to $45 \%$ for capital transfers in July 1981 (see IMF, 2008).

In June 1982, the Bank of Mauritius again intervened in the foreign market by delinking the rupee from the SDR. The rupee was then pegged to a tradeweighted basket of currencies of the country's major trade partners under an IMF liberalization initiative. In spite of these changes, the exchange rate remained pegged de facto to the US dollar with a bandwidth of 5\% (see Broda, 2002; Reinhard and Rogoff, 2004). There was a limit specified on the sale of foreign currency for travelling purposes as a form of capital control. The monetary authorities maintained a multiple currency from this period till the mid-1990s. As part of the multiple currency policy, a tax of $15 \%$ was charged on some capital remittances. This tax remained in operation till 1992 when all forms of exchange rate restrictions were eliminated. The de facto crawling bandwidth was reduced from $5 \%$ to $2 \%$ in 1992. Foreign currency transactions were fully liberalized in July 1994. The country adopted a managed float exchange rate regime from this period onwards. The Bank of Mauritius occasionally intervenes in the foreign exchange market to minimize exchange rate volatilities.

\section{A SIMPLE THEORETICAL MODEL OF THE REAL EXCHANGE RATE}

Although various authors have successfully formulated formal models of the real exchange rate, which incorporates its determinants (see, e.g., Mundell, 1961; McKinnon, 1963; Ostry, 1988; Khan and Ostry, 1991; Faruqee, 1995; Frankel, 1995; Montiel, 1999; Kia, 2013), this paper draws on the model formulated by Edwards 
(1993) largely due to its empirical appeal. This is a simple model of the real exchange rate in which there is simultaneous equilibrium of the current account balance and the tradable good market (see Drine and Rault, 2015).

The basic building blocks of the model entail the following. Suppose there is a small open economy with three sectors, which produces three goods. The sectors are export, import, non-tradable. These sectors produce, respectively, exports $(X)$, imports $(M)$, and non-tradables $(N)$. Suppose that the economy is populated by consumers of the imports and the non-tradables. The economy practices a floating exchange rate regime, so that its floating nominal exchange rate in all transactions is denoted $E$.

In addition to the above assumptions, suppose that $P_{X^{\prime}} P_{M^{\prime}}$ and $P_{N}$ are the prices of exports, imports, and non-tradables, respectively. By taking the world price of exports as the numeraire (i.e. $P_{X}{ }^{*}=1$ ), it holds that the domestic price of exports will be $P_{X}=E P_{X}{ }^{*}=E$. This relation holds directly from the absolute form of the Purchasing Power Parity (PPP) hypothesis. Denote the world price of imports as $P_{M}^{*}$. It is straightforward to define the domestic relative prices of exports $\left(e_{X}\right)$ and imports $\left(e_{X}\right)$ to non-tradables as $E / P_{N}$ and $P_{M} / P_{N^{\prime}}$ respectively. Thus, the relative price of imports to non-tradables can be formulated as (see Drine and Rault, 2015)

$$
e_{M}^{*}=E P_{M}^{*} / P_{N}
$$

Suppose the economy imposes tariffs on imports. Then the price of imports will be

$$
P_{M}=E P_{M}^{*}+\eta, \eta=\text { tariff rate }
$$

Let the total output $(Q)$ in this small open economy be given by the following equation

$$
Q=Q_{X}\left(e_{X}\right)+Q_{N}\left(e_{X}\right), Q_{X}^{\prime}>0 \text { and } Q_{N}^{\prime}<0
$$

Similarly, let private consumption $(C)$ in the economy be defined by the following

$$
C=C_{M}\left(e_{M}\right)+C_{N}\left(e_{M}\right), C_{M}^{\prime}<0 \text { and } C_{N}^{\prime}>0
$$

where $C_{M}$ and $C_{N}$ denote, respectively, consumption on imports and nontradables.

A few more equations will close the model. In the spirit of Cassel (1918), define the real exchange rate $(e)$ for this economy as the relative price of tradables to nontradables. That is

$$
e=\rho e_{M}+(1-\rho) e_{X}=E\left(\rho P_{M}^{*}+(1-\rho)\right)+\rho \eta / P_{N}, \rho \in(0,1)
$$

Now, suppose that capital in this economy is perfectly mobile, and denote net foreign assets of the economy by $A$. Suppose also that this economy invests its net foreign assets at the international real interest rate $r^{*}$. Then, the economy's 
Current Account ( $C A)$ in any given year will be the sum of its net interest earnings on $A$ and its trade surplus (i.e. $X-M$ ). This is given by the following expression (see Drine and Rault, 2015)

$$
C A=r^{*} A+Q_{X}\left(e_{X}\right)-P_{M}^{*} C_{M}\left(e_{M}\right)
$$

In addition, define a change in the foreign currency reserves $(R)$ in the economy as

$$
R=C A+K I
$$

where KI denotes net capital inflows. Assume that in the short and the intermediate period the economy may lose or gain foreign currency reserves. Then it follows that the current account of this economy is sustainable if the current account deficit plus the net capital inflows in the long-run sum up to zero. This holds that the official reserves of the economy do not change. Thus, the economy is in an external equilibrium if the sum of the current account balance and the capital account balance equal to zero. This can be expressed as follows (see Edwards, 1993)

$$
\begin{aligned}
& r^{*} A+Q_{X}\left(e_{X}\right)-P_{M}^{*} C_{M}\left(e_{M}\right)+K I=0 \\
& C_{N}\left(e_{M}\right)+G_{N}=Q_{N}\left(e_{X}\right)
\end{aligned}
$$

where $G_{N}$ is public spending on non-tradables. Thereby, the equilibrium real exchange rate is the rate, which ensures, simultaneously, external and internal equilibrium. Thus, using Eqs. (3.8) and (3.9), we can formulate the equilibrium real exchange rate $\left(e^{*}\right)$ as a function of $\eta, r^{*}, P_{M}^{*}, A, K I$, and $G_{N}$ (see Drine and Rault, 2015). That is.

$$
e^{*}=e^{*}\left(\eta, r^{*}, P_{M}^{*}, A, K I, G_{N}\right)
$$

To reiterate, the equilibrium real exchange rate depends on the trade policy (i.e. trade openness), foreign interest rate, terms of trade ${ }^{3}$, foreign capital flows ${ }^{4}$, and public spending ${ }^{5}$. In principle, these are the most often identified determinants of the real exchange rate in the long-run (see Elbadawi and Soto, 1994; Cardenas, 1997; Loayza and Lopez, 1997; Montiel, 1999; Aron et al., 2000; MacDonald and Ricci, 2003; Iman and Minoiu, 2011; Drine and Rault, 2015).

Other variables such as the world commodity prices (see Cashin et al., 2002; Chen and Rogoff, 2002; MacDonald, 2002; MacDonald and Ricci, 2003), real money supply (see Kia, 2013), real productivity (see Detken et al., 2002; Kia, 2013; Drine

3 See Montiel (1997), Goldfajn and Valdes (1999), and Imam and Minoiu (2011).

4 See Lane and Milesti-Ferretti (2000), MacDonald and Ricci (2003), Imam and Minoiu (2011).

5 See De Gregorio et al. (1994), Montiel (1997), MacDonald and Ricci (2003), and Imam and Minoiu (2011). 
and Rault, 2015), and foreign direct investment (see Drine and Rault, 2015) have also been identified in the literature as macroeconomic determinants of the real exchange rate. These variables are utilized in our paper.

On the empirical front, different approaches have been utilized to estimate the functional relationship in Eq. (3.10). Each approach has its advantages and drawbacks. We utilized the Bayesian Model Averaging (BMA) to estimate this function. We discuss this approach in the next section.

\section{MODEL SPECIFICATION AND PRIOR STRUCTURES}

We analyze the core macro determinants of the real exchange in Mauritius using BMA. This approach is very useful in the sense that it addresses model uncertainty in a canonical regression specification (see Hoeting et al., 1999). To make this point clear, let us assume that our model is a linear regression of the following form

$$
y=\alpha_{\gamma}+X_{\gamma} \beta_{\gamma}+\varepsilon, \quad \varepsilon \sim N\left(0, \sigma^{2} I\right)
$$

where $y$ is the dependent variable (i.e. the real exchange rate), $\alpha$, and $\beta_{\gamma}$ denote the intercept and the coefficient terms, respectively, $X_{\gamma}$ is a matrix of explanatory variables (i.e. the macro determinants of the real exchange rate), $\varepsilon$ is an IID error term whose variance is $\sigma^{2}$.

The question of interest is which variables should enter into the matrix $X_{\gamma^{\prime}}$ among a host of potential explanatory variables? Answering this is important because there is a universe of explanatory variables $X$ that may explain the variation in $y$. In principle, the choice of $X_{\gamma} \in\{X\}$ to be included in the model must be based on their relative importance. In the canonical linear regression problem, a single model contains all the explanatory variables, rendering the approach inefficient or even infeasible with a limited number of observations (see Chipman et al., 2001).

The BMA approach emends this model uncertainty problem by estimating models for all possible combinations of $\{X\}$ and constructing a weighted average over all of them (see Feldkircher and Zeugner, 2015). Supposing that $X$ contains $K$ potential variables, the BMA approach entails that we estimate $2^{K}$ models, which is represented by the model candidate space $M=\left\{M_{1^{\prime}}, M_{2^{\prime}}, \ldots, M_{2^{K}}\right\}$. Bayes theorem provides the useful guide for obtaining model weights, which are estimated from the posterior model probabilities. Using the Bayes theorem, we have that

$$
p\left(M_{\gamma} \mid y, X\right)=\frac{p\left(y \mid M_{\gamma}, X\right) p\left(M_{\gamma}\right)}{p(y \mid X)}=\frac{p\left(y \mid M_{\gamma}, X\right) p\left(M_{\gamma}\right)}{\sum_{s=1}^{2^{K}} p\left(y \mid M_{s}, X\right) p\left(M_{s}\right)}
$$

where $p(y \mid X)$ is the integrated likelihood which is constant over all models and it is thus simply a multiplicative term. Hence, the Posterior Model Probability (PMP) is proportional to the integrated likelihood $p\left(y \mid M_{\gamma^{\prime}} X\right)$, which reflects the probability of the data given model $M_{\gamma}$.

The term $p\left(y \mid M_{\gamma}, X\right) p\left(M_{\gamma}\right)$, the product of the marginal likelihood of model $M_{\gamma}$ and the prior model probability $p\left(M_{\gamma}\right)$, shows how the researcher believes model $M_{\gamma}$ is probable prior to observing the data. $p(y \mid X)$ and $p\left(y \mid M_{\gamma}, X\right)$ are different in the 
sense that integration is done over the model space $p(y \mid X)$ but for a given model over the parameter space $p\left(y \mid M_{,} X\right)$. We can infer the Posterior Model Probabilities (PMPs) and the model weighted posterior distribution for any statistic $\theta$ (e.g., the estimator of the coefficient $\beta_{\gamma}$ ), by renormalization $E q$. (4.2) such that

$$
p(\theta \mid y, X)=\sum_{\gamma=1}^{2^{K}} p\left(y \mid M_{\gamma}, y, X\right) \frac{p\left(M_{\gamma} \mid X, y\right) p\left(M_{\gamma}\right)}{\sum_{s=1}^{2^{K}} p\left(M_{s} \mid y, X\right) p\left(M_{s}\right)}
$$

Eq. (4.3) is very crucial because all relevant posterior computations are based on it. For example, we can compute the posterior moments of the coefficient vector $\beta$, which is a weighted average over all models. In a similar fashion, we can also compute the Posterior Inclusion Probabilities (PIPs), which can be used to evaluate the importance of each explanatory variable (i.e. the macro determinants) in the model. This is computed as the sum of probabilities for all models in which the covariate is included (see Feldkircher and Zeugner, 2015).

In practice, the elicitation of the model prior $p\left(M_{\gamma}\right)$ reflects the prior believes of the researcher. A wide range of model priors exists in the literature. As argued by Crespo Cuaresma et al., (2014), majority of the studies have utilized diffuse priors, thereby assigning equal probability to all possible models. This translates to imposing a mean prior model size of $K / 2$. Contrary to these studies, other studies have assigned more prior weight to relatively pragmatic models by assuming Bernoulli distributions with fixed parameter $\pi$ on the inclusion probability for each variable and using the expected model size, $\pi K$, to elicit the prior (see Sala-iMartin et al., 2004). Nevertheless, the recent literature has advanced the elicitation of Binomial-Beta prior distribution. Ley and Steel (2009) argued in favour of this prior, using the original ideas presented in Brown et al. (1998). Essentially, this prior elicitation strategy imposes a Beta hyperprior distribution on $\pi$, which happens to be the parameter of the Bernoulli distribution for the inclusion of each explanatory variable in the model. Ley and Steel (2009) argued that this prior elicitation strategy is powerful because it admits very different prior structures on the model size (see Crespo Cuaresma et al., 2014). We utilize the Binomial-Beta prior and compare it performance against other competing priors.

In the BMA literature, the reliability of the regression coefficients depends heavily on the prior structure imposed by the researcher. Practically all Bayesian linear models build on the Zellner's g prior structure (1986). The value of the Zellner's g prior corresponds to the degree of prior uncertainty (see Feldkircher and Zeugner, 2015). Majority of the studies in the literature have favoured the imposition of a fixed g prior. For example, Fernández et al. (2001) have argued for a comparatively large g prior to minimize prior impact on the results, stay close to the OLS coefficients, and represent the absolute lack of prior knowledge. In contrast, Ciccone and Jarociński (2010) have shown that a large g can be nonrobust to noise innovations, thereby exposing the model to over-fitting problems. Eicher et al. (2011) favoured the choice of intermediate fixed values for the g priors, whereas Liang et al. (2008) argued for default specifications (see Feldkircher and Zeugner, 2015). 
The fixed g prior approach has, however, been heavily criticized to be very vulnerable to unintended consequences. Indeed, Feldkircher (2012) argued that under a large $g$ (i.e. when the shrinkage factor is near unity), the posterior estimates could be over-fitted. Under this condition, the coefficients are poorly estimated, whilst the Posterior Model Probabilities (PMPs) are concentrated. Model sizes become smaller, leading to skewed PIP distribution (see Feldkircher, 2012). In contrast to this, when the g prior is low, the data signals will not be sufficiently exploited, thereby leading to very similar intermediate PIPs for a large share of covariates (see Feldkircher, 2012). To emend this problem, the recent literature has argued for flexible g priors. Liang et al. (2008) have provided an excellent survey of these studies. Following the lead of Liang et al. (2008), we imposed a hyperprior on $\mathrm{g}$. We set the expected prior value of the shrinkage factor to the Uniform Information Prior (UIP) and compare its PIPs to other competing flexible g priors.

We sample the posterior distributions of interest over the model space using the birth/death Markov Chain Monte Carlo Model Composite $\left(\mathrm{MC}^{3}\right)$ sampler 6 The sampler is the commonly utilized in the BMA literature. The sampling is done such that one of the covariates is randomly selected at a time. Given that the covariate selected is already included in the present model, say $M_{i}$, it holds that the candidate model, say $M_{i}$ will contain the same set of covariates as $M_{i}$ except that the selected covariate will be discarded. Given that the covariate selected is not in $M_{i}$, then the candidate model will contain all the covariates from $M_{i}$ in addition to the selected covariate (see Feldkircher and Zeugner, 2015).

\section{THE EMPIRICAL RESULTS}

The dataset is annual and contains 22 macroeconomic variables over the period 1976-2012. The definition and source of each of these variables are in the Data Appendix. Where the original data is measured in current terms, we adjusted it to constant terms using national price data. The variables are in two categories. The first category consists of the frequently identified macro determinants of the real exchange rate in the literature. These include, among others, trade openness, foreign interest rate, terms of trade, world commodity prices, net foreign assets, and public spending. The second category consists of other variables, which may influence the real exchange rate but are largely overlooked in the literature. These variables are, among others, average interest on new external debt commitments, debt service on external debt, real domestic investment, domestic inflation, real net official development assistance and official aid received, and the growth of the world economy. All the variables are demeaned to invoke stationarity.

The empirical results are presented in threefold. In the first, we evaluate the macro determinants of the real exchange rate using our baseline specification. This specification uses the Binomial-Beta distribution (as in Liang et al., 2008, and Feldkircher, 2012; Crespo Cuaresma et al., 2014) on the model prior, and imposes a hyperprior on $g$ with the expected prior value of the shrinkage factor restricted to the UIP. In all cases, except in the case of the tessellation prior, we sampled the

6 Refer to Stephens (2000), and LeSage and Parent (2007) for excellent description of this sampler. See also the Technical Appendix. 
posterior distributions of interest over the model space using the birth/death $\mathrm{MC}^{3}$ sampler. In the second, we evaluate the robustness of these macro determinants to alternative elicitation of flexible Zellner's g priors. Here, we compare the PIPs of $\mathrm{g}=\mathrm{UIP}$ to competing flexible $\mathrm{g}$ priors such as $\mathrm{g}=\mathrm{RIC}^{7}, \mathrm{~g}=\mathrm{BRIC}^{8}$, and $\mathrm{g}=\mathrm{EBL}^{9}$. Finally, we recognize that under this setting, the inclusion of several macro determinants can pose multicollinearity problems. Hence, we controlled for multicollinearity in the macro determinants using three competing model priors namely: the tessellation prior (see George, 2010), the weak heredity prior (see Chipman, 1996), and the general dilution prior (see Chipman, 1996). In the tessellation prior case, we utilize the $\mathrm{MC}^{3}$ tessellation sampler proposed in George (2010). We maintain the flexible hyperprior $\mathrm{g}=\mathrm{UIP}$ for these competing model priors and compare their PIPs with the benchmark model.

\subsection{Macro Determinants of the Real Exchange Rate}

Table 2 shows the results stemming from our benchmark specification of the model prior structure, and the results based on alternative specifications of the flexible Zellner's g prior on the regression coefficients. Each of the columns in Table 2 reports, respectively, the Posterior Inclusion Probabilities (PIPs) of each macro determinant of the real exchange rate, the Posterior Mean (PM), and the Posterior Standard Deviation (PSD) of the posterior distribution for the associated parameter. These results are based on 6,000,000 draws of the $\mathrm{MC}^{3}$ sampler, 3,000,000 burn-in iterations, and a Binomial-Beta prior for the model size expected to be $\mathrm{K} / 2$ explanatory variables. As a rule of thumb, the importance of the macro determinants in the model can be interpreted in terms of their PIPs as follows: $50-75 \%$ PIP is weak, 75-95\% PIP is substantial, 95-99\% PIP is strong, and 99\%+ PIP is decisive (see Kass and Raftery, 1995; Eicher et al., 2009; Crespo Cuaresma et al., 2014). Hence, an explanatory variable whose PIP is greater than the threshold of 0.5 is adjudged as robust (see Crespo Cuaresma et al., 2014).

The second column in Table 2 reports the results for the benchmark model, which is based on 21 macro determinants of the real exchange rate (see Data Appendix for details). The real money supply and the real productivity, as proxy by LNRMS and LNRGDP, respectively, are identified as the robust macro determinants of the real exchange rate in Mauritius. The coefficients of these robust macro determinants have the expected signs (see Figure 4). The real money supply impact on the real exchange rate negatively, which is consistent with the theory. Higher real money supply stimulates increases in the domestic price level,

7 RIC denotes the risk inflation criterion proposed by Foster and George (1994), whereby the hyperprior on $g$ is set to $K^{2}$. K denotes the total number of covariates in the model.

8 BRIC denotes the benchmark risk inflation prior proposed by Fernández et al. (2001), whereby the hyperprior on $g$ is set to $\max \left(N, K^{2}\right)$. $N$ is the total number of observations.

9 EBL denotes the local empirical Bayes prior advocated by George and Foster (2000), and Hansen and $\mathrm{Yu}(2001)$, whereby the hyperprior on $\mathrm{g}$ is set to $g_{\gamma}=\operatorname{argmax}_{g} p\left(y \mid M_{\gamma}\right.$ $, X, g)$. Here, the information contained in the data $(y, X)$ is used to elicit $g$ via maximum likelihood. 
which in turn lowers the real exchange rate in the long-run (see Kia, 2013). The real productivity, in contrast, impact on the real exchange rate positively. Increasing real productivity enhances the earning capacity of the labour force. This is translated into higher real demand for money, which lowers domestic price level, thereby leading to higher real exchange rate (see Kia, 2013). However, whereas the posterior standard deviation is relatively small for the real money supply, it has been high for the real productivity. Therefore, the real money supply appears to be the more reliable macro determinant of the real exchange rate in Mauritius than the real productivity.

Figure 1 displays the marginal posterior densities for the coefficients of the robust macro determinants of the real exchange rate based on 5000 models (i.e. coefficients with the largest PIPs). The upper panel of Figure 1 shows the posterior distribution of the coefficient of the real money supply. This distribution is very concentrated around the posterior mean of -0.477 with a PIP of $99.95 \%$. Similarly, the lower panel of Figure 1 shows the posterior distribution of the coefficient of the real productivity. This distribution is also very concentrated around the posterior mean of 0.748 with a PIP of $97 \%$. These marginal posterior densities clearly show that the real money supply and the real productivity explain the real exchange rate in Mauritius.

\subsection{Robustness of the Results to Alternative Elicitation of Zellner's g Priors}

As argued earlier (see Section 4), the choice of the prior structure on the regression coefficients can have massive influence on the posterior estimates. This issue has generated considerable discussion in the BMA literature (see Liang et al., 2008; Ciccone and Jarociński, 2010; Eicher et al., 2011; Feldkircher, 2012). Recent studies have argued for the use of hyper-g prior structure to avoid unintended posterior consequences (see Liang et al., 2008; Feldkircher, 2012). In this section, we evaluate the robustness of these macro determinants to alternative elicitation of hyper-g priors. Specifically, we compare the PIPs of g=UIP to competing hyper-g priors such as g=RIC, g=BRIC, and g=EBL. The third, fourth, and fifth columns of Table 2 report the PIPs, PMs, and PSDs of these different elicitation of Zellner's $\mathrm{g}$ prior. The posterior estimates of these different hyper-g priors are remarkably similar to the benchmark specification (i.e. $g=\mathrm{UIP}$ ) in column two of Table 2. A better way to appreciate the similarity is by looking at Figure 2, which shows the Posterior Inclusion Probabilities (PIPs) and the standardized coefficients based on the four different flexible Zellner's g prior structures. The upper panel plots the PIPs, whereas the lower panel plots the standardized coefficients. By carefully observing Figure 2, we can see that the earlier results remain robust to different flexible Zellner's g prior structures (albeit, the PIPs based on the g=EBL diverged minimally). Therefore, the real money supply and the real productivity remain the robust macro determinants of the real exchange rate in Mauritius.

\subsection{Controlling for Multicollinearity in the Macro Determinants}

In this section, we tackle a critical issue, which can render the results inefficient multicollinearity. We have estimated a model, which contains several explanatory 
variables. In theory, these variables are related. This means that we cannot ignore a potential multicollinearity problem among the variables. Some authors have devoted much attention to dealing with this problem in the Bayesian literature (see Chipman, 1996; George, 2010). To assess the robustness of the macro determinants to multicollinearity, we employ three priors on the model size, namely: (i) the weak heredity prior (see Chipman, 1996); (ii) the general dilution prior (see Chipman, 1996); and (iii) the tessellation prior (see George, 2010). In the case of the tessellation prior, we utilize the MCMC tessellation sampler proposed in George (2010). We maintain the flexible hyperprior g=UIP for these competing model priors and compare their PIPs with the benchmark model. In all cases, the estimated results are based on 6,000,000 draws and 3,000,000 burn-in iterations. These results are reported in Table 3. Clearly, the estimated results for the robust macro determinants are very similar, except in the case of the weak heredity prior where the posterior coefficients are slightly overestimated. The evidence is even clearer if we carefully observe Figure 3, which displays the Posterior Inclusion Probabilities (PIPs) and the standardized coefficients based on the four different specifications of model prior structure for the model size. The upper panel shows the PIPs, whereas the lower panel shows the standardized coefficients. That the posterior results based on the weak heredity prior diverged from the rest is to be expected because this prior deal better with multicollinearity introduced by interaction terms (see Chipman, 1996). In essence, our results appear unaffected by different elicitation of priors on the model size. Therefore, the real money supply and the real productivity remain the robust macro determinants of the real exchange rate in Mauritius.

\section{CONCLUDING REMARKS}

This paper examines the robust macro determinants of the real exchange rate in Mauritius under model uncertainty by utilizing the BMA approach. The paper brings some new contributions into the literature. First, it utilizes a broader range of potential macro determinants of the real exchange rate in Mauritius. Second, it tackles the issue of model uncertainty when identifying these macro determinants of the real exchange rate. The paper does this by exploring the impact of different priors on the model size, and different priors on model coefficients on the posterior estimates. When the BMA approach is utilized this way, the paper avoids unintended consequences of eliciting inappropriate priors, and dealing sufficiently with multicollinearity issues.

The paper finds the real money supply, and the real productivity to be the robust macro determinants of the real exchange rate in Mauritius. These two robust macro determinants yield coefficient signs that are theoretically consistent. The real money supply impact on the real exchange rate negatively, whereas the real productivity impact on the real exchange rate positively. On the one hand, higher real money supply stimulates increases in the domestic price level, which in turn lowers the real exchange rate in the long run. On the other, increasing real productivity enhances the earning capacity of the labour force. This is translated into higher real demand for money, which lowers domestic price level, thereby leading to higher real exchange rate. 


\section{REFERENCES}

Aron, J., Elbadawi, I., and Kahn, B. (2000). "Real and Monetary Determinants of the Real Exchange Rate in South Africa," in Development Issues in South Africa, Ed. By Ibrahim Elbadawi, I., and Hartzenberg, T. (London: Macmillan).

Broda, C. (2002). Terms of Trade and Exchange Rate Regimes in Developing Countries. Federal Reserve Bank of New York.

Brown, P., Vannucci, M., and Fearn, T. (1998). Multivariate Bayesian Variable Selection and Prediction. Journal of the Royal Statistical Society B, 60:627-641.

Cardenas, M. (1997) La Tasa de Cambio en Colombia (Bogota: Cuadernos Fedesarallo).

Cashin, P., Cespedes, L., and Sahay, R. (2002). Developing Country Real Exchange Rates: How Many are Commodity Countries?. IMF Working Paper 02/223 (Washington: International Monetary Fund).

Cassel, G. (1918). Abnormal Deviations in International Exchanges. The Economic Journal 28(112): 413-415.

Chen, Y-C., and Rogoff, K. (2002). Commodity Currencies and Empirical Exchange Rate Puzzles. IMF Working Paper 02/27 (Washington: International Monetary Fund).

Chipman, H. (1996). Bayesian Variable Selection with Related Predictors. Canadian Journal of Statistics, 24:17-36.

Chipman, H., George, E., and McCulloch, R. (2001). The Practical Implementation of Bayesian Model Selection. Institute of Mathematical Statistics Lecture Notes Monograph Series Vol. 38. Beachwood, Ohio.

Ciccone, A., and Jarociński, M. (2010). Determinants of Economic Growth: Will Data Tell?. American Economic Journal: Macroeconomics, 2(4): 222-246.

Clark, P.B. and R. MacDonald. (1999). "Exchange Rates and Economic Fundamentals: A Methodological Comparison of BEERs and FEERs" in R. MacDonald and J Stein (eds) Equilibrium Exchange Rates, Kluwer: Amsterdam. And IMF Working Paper 98/67 (Washington: International Monetary Fund, March 1998)

Crespo Cuaresma, J., Doppelhofer, G., and Feldkircher, M. (2014). The Determinants of Economic Growth in European Regions. Regional Studies 48(1): 44-67.

De Gregorio, J., Giovannini, A., and Wolf, H. (1994). International Evidence on Tradables and Nontradables Inflation. European Economic Review 38:1225-44.

Detken, C., Dieppe, A., Henry, J., Smets, F., and Marin, C. (2002). Determinants of the Effective Real Exchange Rate of the Synthetic Euro: Alternative Methodological Approaches. Australian Economic Papers 41(4): 404-436.

Driver, R., and Wren-Lewis, S. (1997). Real Exchange Rates in the Year 200 (Washington: Institute for International Economics).

Drine, I., and Rault, C. (2015). "Learning about the Long-Run Determinants of Real Exchange Rates for Developing Countries: A Panel Data Investigation" in Panel Data Econometrics Theoretical Contributions and Empirical Applications 307325.

Edwards, S. (1993). Openness, Trade Liberalization, and Growth in Developing Countries. Journal of Economic Literature 31 (3):1358-1393.

Edwards, S. (1994). "Real Monetary Determinants of Real Exchange Rate Behavior: Theory and Evidence from Developing Countries," in Estimating Equilibrium 
Exchange Rates, ed. by J. Williamson (Washington: Institute for International Economics).

Elbadawi, I., and Soto, R. (1994). Capital Flows and Long-Term Equilibrium Real Exchange Rates: Chile (Unpublished, Washington: World Bank).

Eicher, T. S. and Papageorgiou, C., and Raftery, A. E. (2011). Default priors and predictive performance in Bayesian model averaging, with application to growth determinants. Journal of Applied Econometrics 26(1): 30-55.

Faruqee, H. (1995). Long-Run Determinants of the Real Exchange Rate: A StockFlow Perspective. IMF Staff Papers, Palgrave Macmillan, 42(1): 80-107.

Feldkircher, M. (2012). Forecast Combination and Bayesian Model Averaging: A Prior Sensitivity Analysis. Journal of Forecasting, 31(4): 361-376.

Feldkircher, M. and Zeugner, S. (2015). Bayesian Model Averaging Employing Fixed and Flexible Priors: The BMS Package for R. Journal of Statistical Software $68(4)$.

Fernández, C., Ley, E., and Steel, M. F. (2001). Benchmark Priors for Bayesian Model Averaging. Journal of Econometrics, 100:381-427.

Foster, D. P., and George, E. I. (1994). The Risk Inflation Criterion for Multiple Regression. The Annals of Statistics, 22:1947-1975.

Frankel, J. (1995). Monetary Regime Choice for a Semi-Open Country, in Capital Controls, Exchange Rates and Monetary Policy in the World Economy, edited by Sebastian Edwards, (Cambridge, England: Cambridge University Press).

GEM Commodities. (2014). http://data.worldbank.org/data-catalog/commodityprice-data.

George, E. I. (2010). Dilution Priors: Compensating for Model Space Redundancy." In Berger, J. O., Cai, T. T., and Johnstone, I. M. (eds.), Borrowing Strength: Theory Powering Applications, Festschrift for Lawrence D. Brown, Volume 6 of Collections, pp. 158-165. Institute of Mathematical Statistics, Beachwood, Ohio, USA.

George, E. I., and Foster, D. P. (2000). Calibration and Empirical Bayes Variable Selection. Biometrika, 87(4), 731-747.

Ghei, N., and Pritchett, L. (1999). "The Three Pessimisms: Real Exchange Rates and Trade Flows in Developing Countries," in Exchange Rate Misalignment: Concepts and Measurement for Developing Countries, ed. by L. Hinkle and P. Montiel (New York: Oxford University Press for the World Bank).

Goldfajn, I., and Valdes, R. (1999). The Aftermath of Appreciations. Quarterly Journal of Economics. Vol. 114 (February), Pp. 229-62.

Hansen, M. H., and Yu, B. (2001). Model Selection and the Principle of Minimum Description Length. Journal of the American Statistical Association, 96(454): 746774.

Hinkle, L., and Montiel, P. J. (1999). Estimating Equilibrium Real Exchange Rates in Developing Countries (New York: Oxford University Press for the World Bank).

Hoeting, J. A., Madigan, D., Raftery, A. E., and Volinsky, C. T. (1999). Bayesian Model Averaging: A Tutorial. Statistical Science, 14, No. 4:382-417.

Imam, P. and Minoiu, C. (2011). The Equilibrium Exchange Rate of Mauritius: Evidence from Two Structural Models. Emerging Markets Finance E Trade / November-December 2011, Vol. 47, No. 6, pp. 134-147. 
IMF. (2008). Mauritius: Selected Issues. IMF Country Report No. 08/237, The International Monetary Fund. Washington DC.

Kass, R. and Raftery, A. (1995). Bayes Factors. Journal of the American Statistical Association, 90:773-795.

Khan, M. S., and Ostry, J. D. (1991). Response of the Equilibrium Real Exchange Rate to Real Disturbances in Developing Countries. IMF Working Papers 91/3 International Monetary Fund.

Kia, A. (2013). Determinants of the Real Exchange Rate in a Small Open Economy: Evidence from Canada. Journal of International Financial Markets, Institutions $\mathcal{E}$ Money 23(1): 163-178.

Lane, P. R., and Milesi-Ferretti, G. M. (2000). Long-Term Capital Movements. NBER Working Paper No. 8366 (Cambridge, MA: National Bureau of Economic Research).

Lee, J., G. M. Milesi-Ferretti, J. Ostry, A. Prati, and Ricci, L. A. (2008). Exchange Rate Assessments: CGER Methodologies. IMF Occasional Paper No. 261 (Washington: International Monetary Fund).

LeSage, J. P. and Parent, O. (2007). Bayesian Model Averaging for Spatial Econometric Models. Geographical Analysis, 39:3:241-267.

Ley, E. and Steel, M. F. (2009). On the Effect of Prior Assumptions in Bayesian Model Averaging with Applications to Growth Regressions. Journal of Applied Econometrics, 24:4:651-674.

Liang, F., Paulo, R., Molina, G., Clyde, M. A., Berger J. O. (2008). Mixtures of g Priors for Bayesian Variable Selection. Journal of the American Statistical Association, 103(481): 410-423.

Loayza, N., and Lopez, H. J. (1997). Misalignment and Fundamentals: Equilibrium Exchange Rates in Seven Latin American Countries (Unpublished, Washington: World Bank).

MacDonald, R. (1995). Long-run Exchange Rate Modeling: A Survey of Recent Evidence. Staff Papers, International Monetary Fund, Vol. 42 (September), pp. 437-98.

MacDonald, R., and Ricci, L. (2003). Estimation of the Equilibrium Real Exchange Rate for South Africa. IMF Working Paper No. 44 (Washington: International Monetary Fund).

McKinnon, R. I. (1963). Optimum Currency Areas. American Economic Review 53(4): 717-725.

Montiel, P. J. (1997). “Exchange Rate Policies and Macroeconomic Management in ASEAN Countries," in Macroeconomic Issues Facing ASEAN Countries, ed. by J. Hicklin, Robinson, D., and Singh, A. (Washington: International Monetary Fund).

Montiel, P. J. (1999). “Determinants of the Long-Run Equilibrium Real Exchange Rate: An Analytical Model," in Exchange Rate Misalignment: Concepts and Measurement for Developing Countries, ed. by L. Hinkle and P. Montiel (New York: Oxford University Press for the World Bank).

Mundell, R. (1961). A Theory of Optimum Currency Areas. American Economic Review, Vol. 51 (September) pp. 627-65. 
Ostry, J. D. (1988). The Balance of Trade, Terms of Trade, and Real Exchange Rate: An Intertemporal Optimizing Framework, Staff Papers, International Monetary Fund, 35: 541-73.

Reinhart, C. M., and Rogoff, K. S. (2004). The Modern History of Exchange Rate Arrangements: A Reinterpretation. Quarterly Journal of Economics 119(1). 1-48.

Sala-i-Martin, X., Doppelhofer, G., and Miller, R. I. (2004). Determinants of LongTerm Growth: A Bayesian Averaging of Classical Estimates (BACE) Approach. American Economic Review, 94:813-835.

Stein, J. L., P. R. Allen, and Associates. (1995). Fundamental Determinants of Exchange Rates. (Oxford, England: Oxford University Press, Clarendon).

Stephens, M. (2000). Bayesian Analysis of Mixture Models with an Unknown Number of Components - An Alternative to Reversible Jump Methods. Annals of Statistics 28: 40-74.

Williamson, J. (1994). Estimating Equilibrium Exchange Rates (Washington: Institute for International Economics).

Zellner, A. (1986). Bayesian Inference and Decision Techniques: Essays in Honor of Bruno de Finetti, chapter On Assessing Prior Distributions and Bayesian Regression Analysis with g-Prior Distributions. North-Holland: Amsterdam. 


\section{Technical Appendix \\ The $\mathrm{MC}^{3}$ Sampler}

Throughout the paper, we utilized the birth/death $\mathrm{MC}^{3}$ sampler, except in the case of the tessellation prior ${ }^{10}$. This section provides a technical description of this sampler. The $\mathrm{MC}^{3}$ sampler performs very well in the BMA setting, as has been shown in numerous studies. In essence, the $\mathrm{MC}^{3}$ sampler is designed such that it wanders efficiently around the model space to observe models with non-negligible posterior mass (see Crespo Cuaresma et al., 2014). The literature offers other $\mathrm{MC}^{3}$ samplers such as the reversible-jump sampler, and the enumeration sampler but we preferred the birth/death sampler due to its approach to choosing covariates in the model space. The iteration is done such that one of the covariates is randomly selected at a time. Given that the covariate selected is already included in the present model, say $M_{i}$, it holds that the candidate model, say $M_{j}$ will contain the same set of covariates as $M_{i}$ except that the selected covariate will be discarded. Given that the covariate selected is not in $M_{i}$, then the candidate model will contain all the covariates from $M_{i}$ in addition to the selected covariate (see Feldkircher and Zeugner, 2015). The sampled candidate model can be compared to the current model by calculating the posterior odds ratio, which gives rise to the acceptance probability as

$$
\hat{p}_{i j}=\min \left[1, \frac{p\left(M_{i}\right) p\left(Y \mid M_{i}\right)}{p\left(M_{j}\right) p\left(Y \mid M_{j}\right)}\right]
$$

${ }^{10}$ See George (2010) for a technical description of the tessellation $\mathrm{MC}^{3}$ sampler. 


\section{Data Appendix}

Table 1. The definition and source of each of the variables we used. They are of two categories. The first category includes variables that are frequently identified as the determinants of the real exchange rate. The second includes variables that may also influence the real exchange rate.

\begin{tabular}{|c|c|c|}
\hline Variable & Full Name & Source \\
\hline RER & Real effective exchange rate & World Development Indicators \\
\hline GCR & The ratio of government consumption to GDP & World Development Indicators \\
\hline OPEN & Trade openness & World Development Indicators \\
\hline TOT & Terms of trade & World Development Indicators \\
\hline NFAR & Net foreign assets to GDP & World Development Indicators \\
\hline WGDPG & The world economic growth & World Development Indicators \\
\hline RCPI & Real commodity price index & Global Economic Monitor \\
\hline RMS & Real Money Supply & World Development Indicators \\
\hline URIR & Real interest rate (\%) & World Development Indicators \\
\hline RDP & Real FDI & World Development Indicators \\
\hline RGDP & GDP (constant 2005 US\$) & World Development Indicators \\
\hline GFCF & Gross fixed capital formation (constant 2005 US\$) & World Development Indicators \\
\hline INF & Inflation, consumer prices (annual \%) & World Development Indicators \\
\hline AVI & Real Average Maturity & World Development Indicators \\
\hline RAM & $\begin{array}{l}\text { Average interest on new external debt } \\
\text { commitments, official (\%) }\end{array}$ & World Development Indicators \\
\hline RDS & Real Debt Service & World Development Indicators \\
\hline IMP & Imports of goods and services (constant 2005 US\$) & World Development Indicators \\
\hline EXP & Exports of goods and services (constant 2005 US\$) & World Development Indicators \\
\hline IVA & Industry, value added (constant 2005 US\$) & World Development Indicators \\
\hline RIP & Real Interest Payments & World Development Indicators \\
\hline MVA & Manufacturing, value added (constant 2005 US\$) & World Development Indicators \\
\hline RODA & $\begin{array}{l}\text { Real Net official development assistance and } \\
\text { official aid received }\end{array}$ & World Development Indicators \\
\hline
\end{tabular}




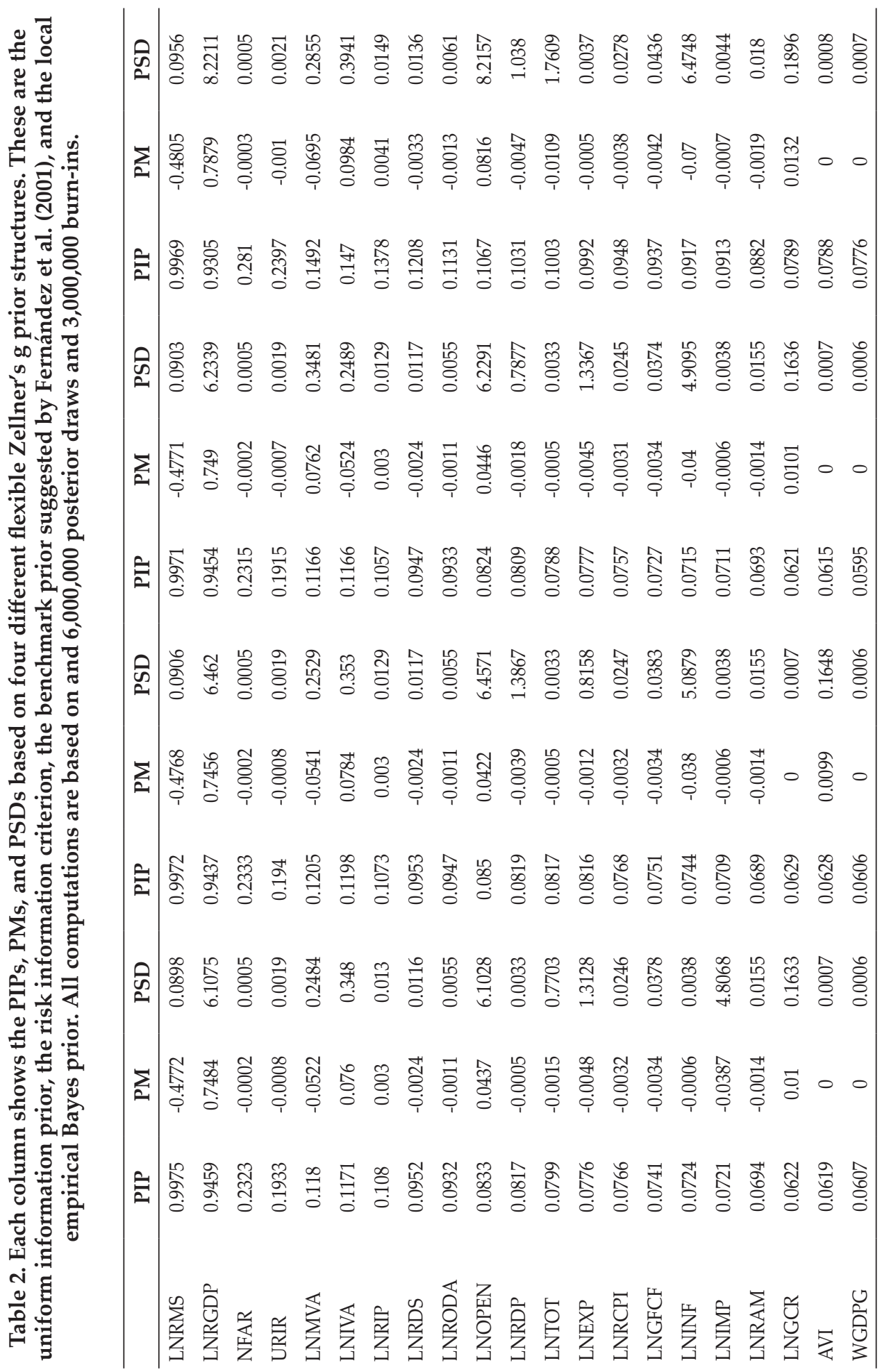




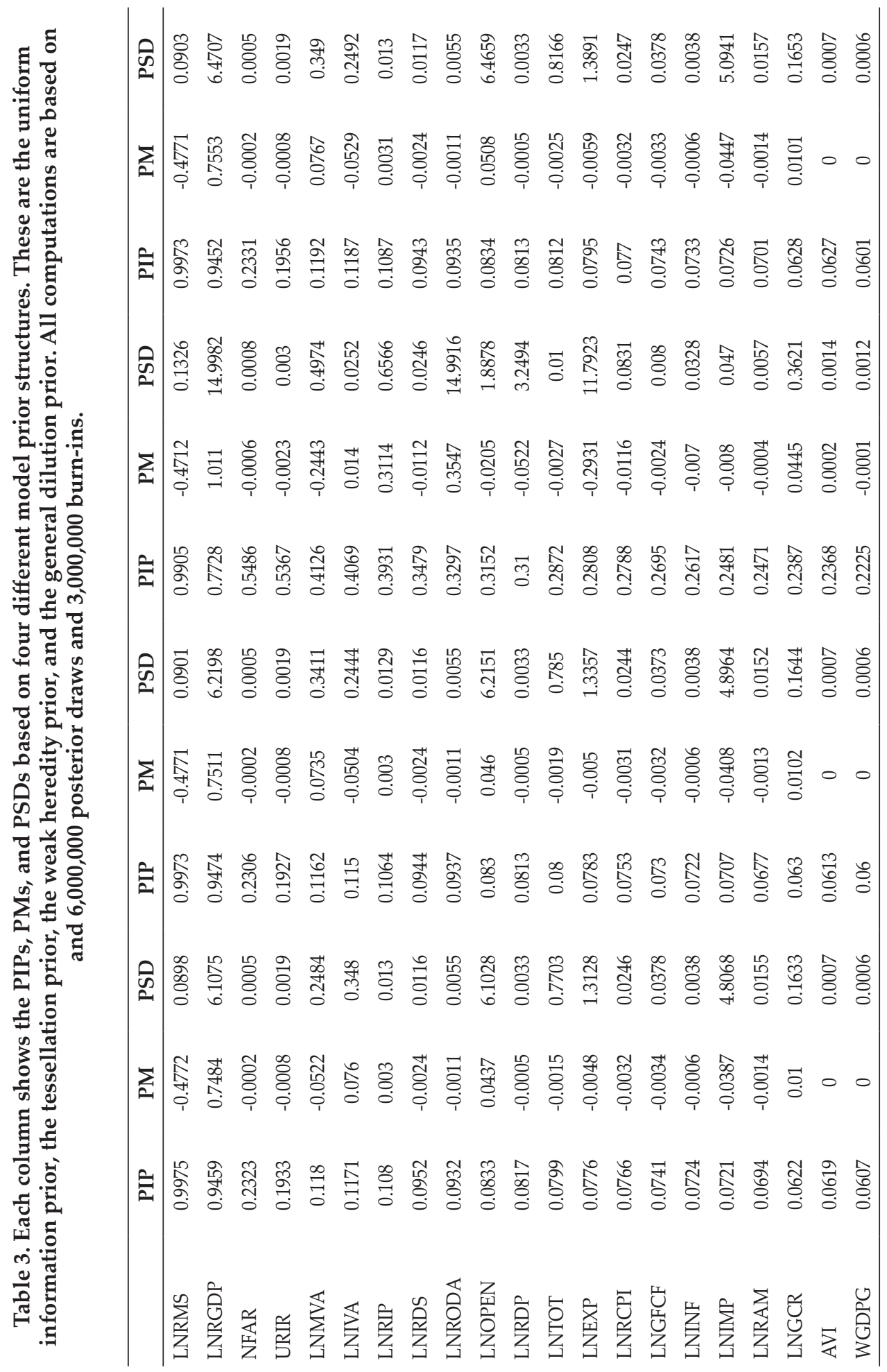



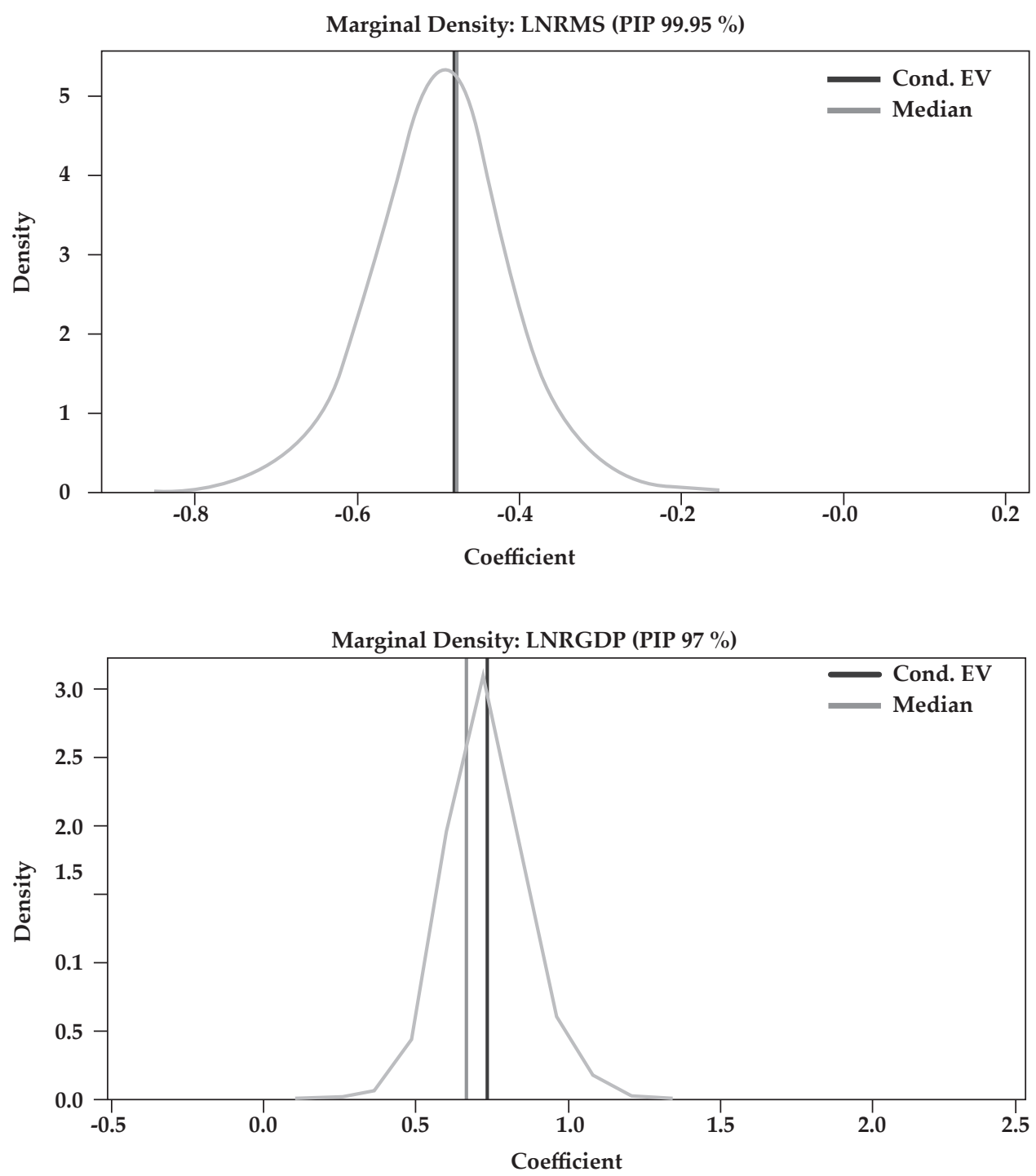

Figure 1. Unconditional posterior distribution of 5000 best models based on the Binomial-Beta distribution and flexible Zellner's g=UIP. The upper panel shows the posterior distribution of the real money supply (LNRMS). The lower panel shows the posterior distribution of the real productivity (LNRGDP). 

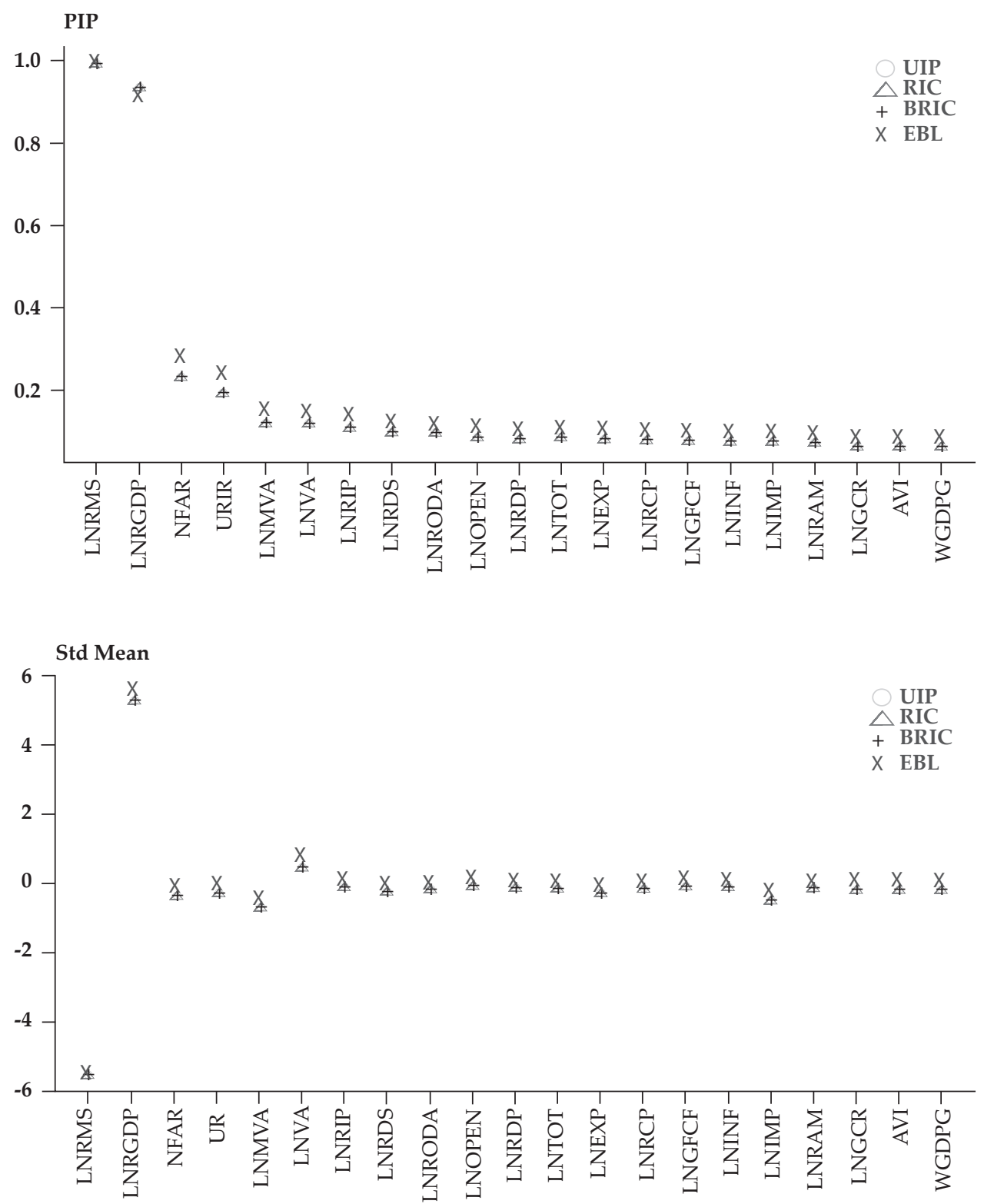

Figure 2. Posterior inclusion probabilities and standardized coefficients based on four different flexible Zellner's g prior structures. UIP=uniform information prior, $\mathrm{RIC}=$ risk information criterion, $\mathrm{BRIC}=$ the benchmark prior suggested by Fernández et al. (2001), and EBL=local empirical Bayes prior. 


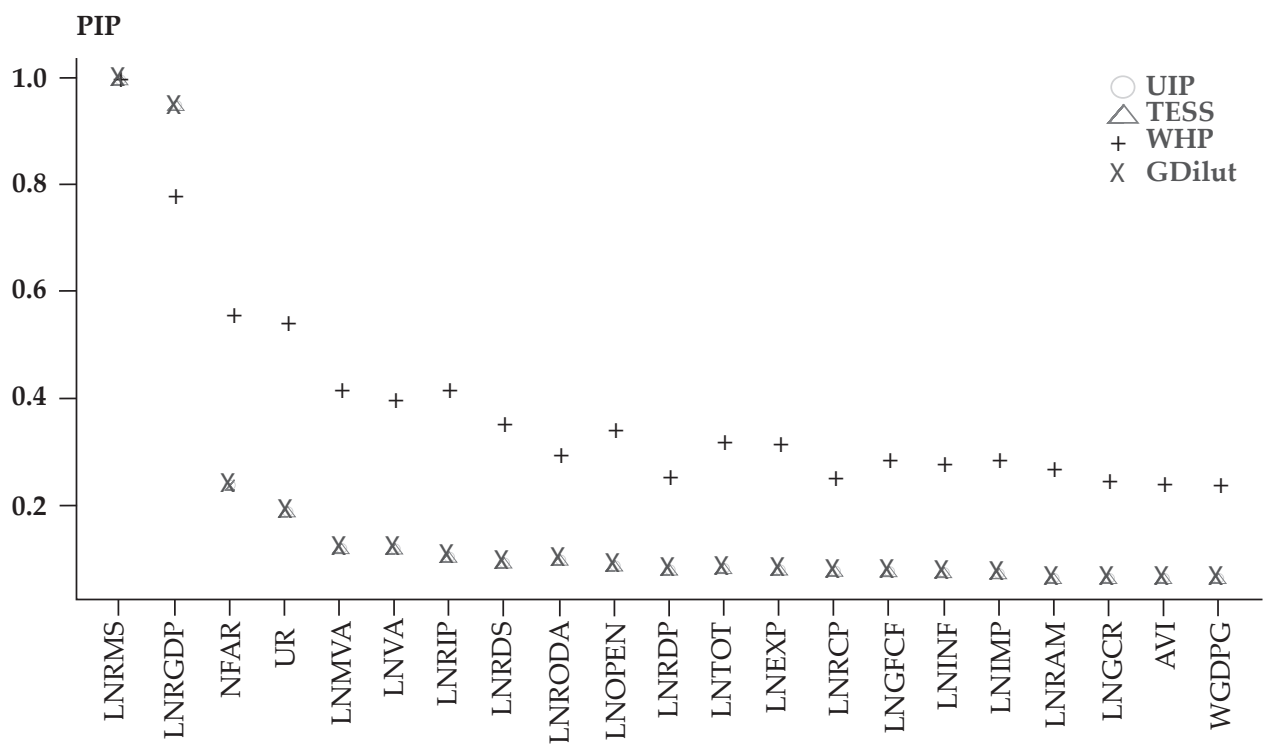

Std Mean

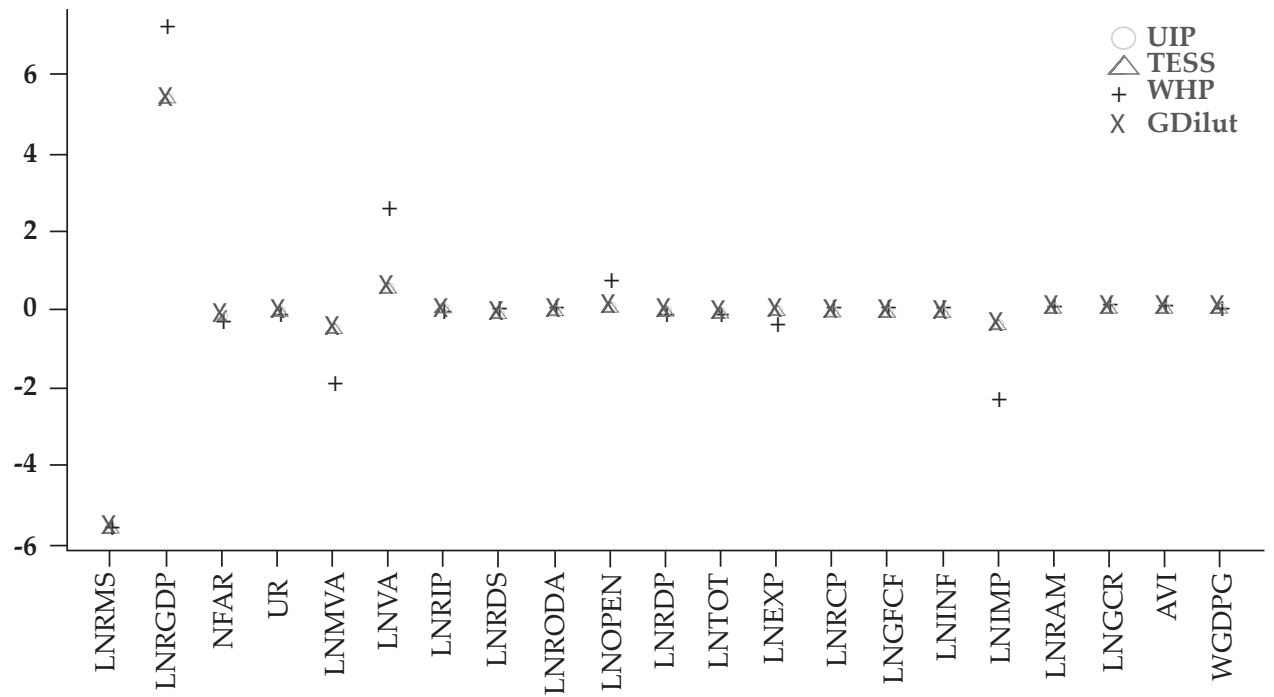

Figure 3. Posterior inclusion probabilities and standardized coefficients based on four different model prior structures. UIP=uniform information prior, TESS=tessellation prior, $\mathrm{WHP}=$ weak heredity prior, and GDilut=general dilution prior. 


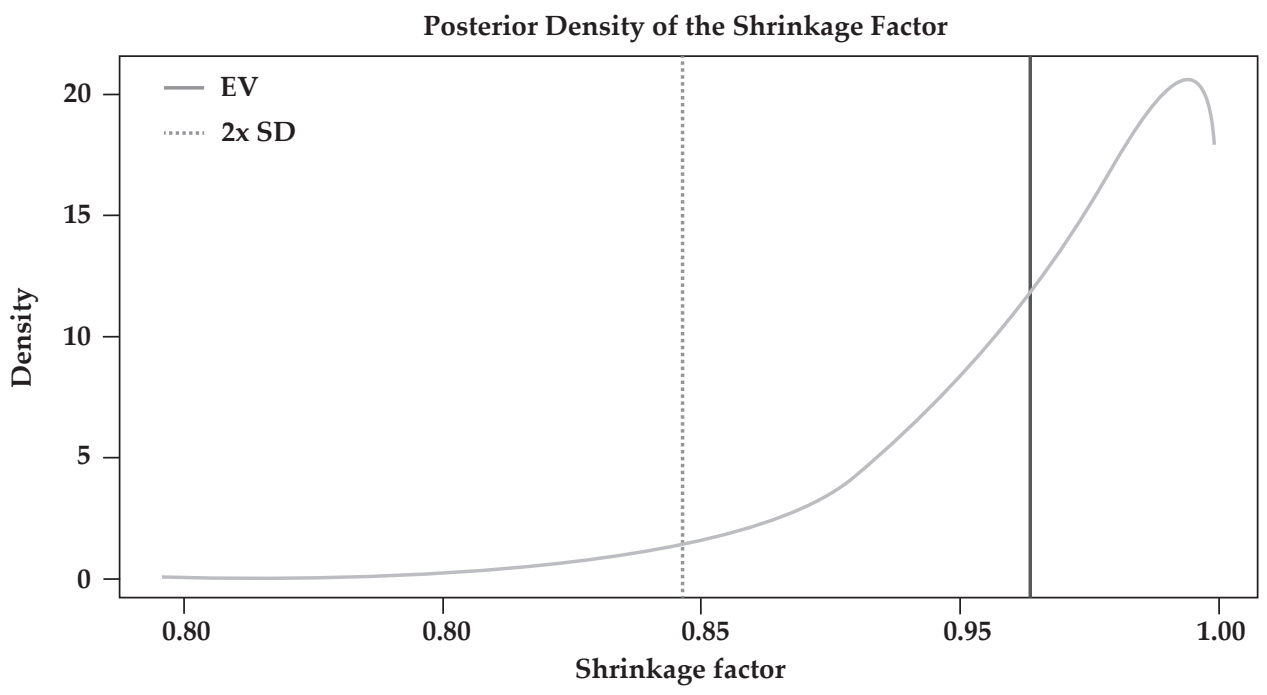

Model Inciusion Based on Best 5000 Models

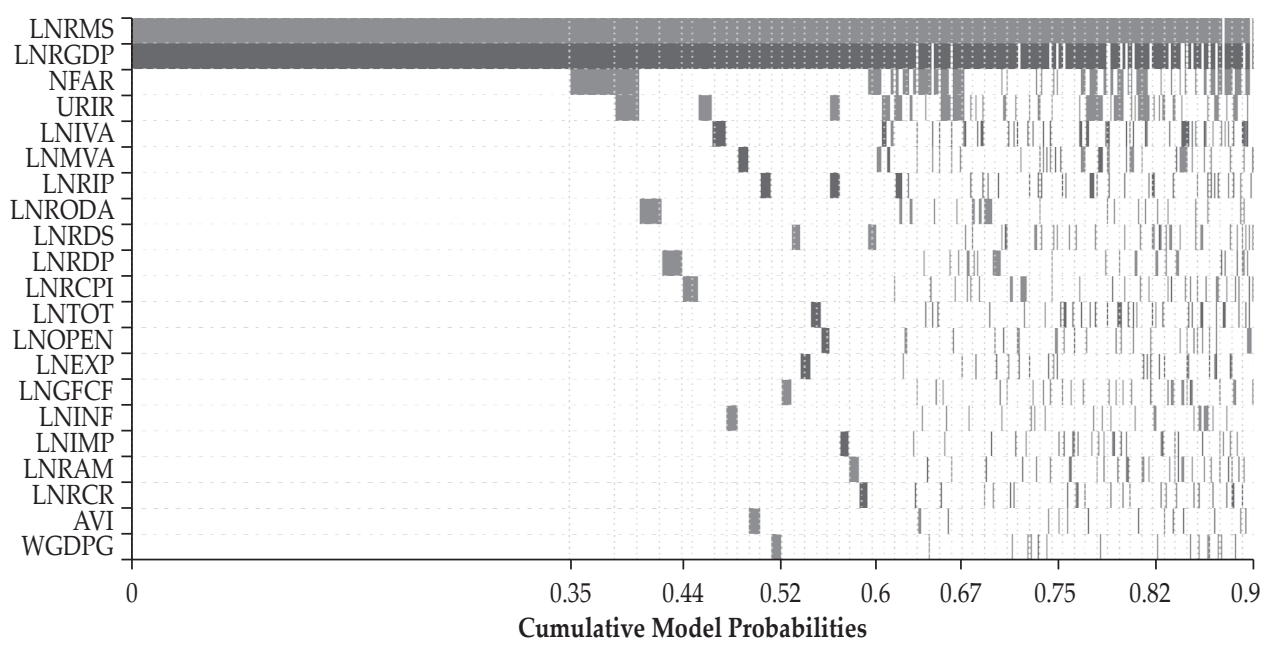

Figure 4. The upper panel shows the posterior density of the shrinkage factor. The solid line corresponds to the expected value, the dashed line corresponds to a \pm 2 standard deviation interval. The lower panel shows the image plot of posterior coefficient signs. The blue color corresponds to a positive coefficient, red to a negative coefficient. 
This page is intentionally left blank 